\title{
Remediation of copper contaminated soil by using different particle sizes of apatite: a field experiment
}

\author{
Jinfeng Xing ${ }^{1,2}$, Tiantian $\mathrm{Hu}^{1}$, Long Cang ${ }^{1 *}$ and Dongmei Zhou ${ }^{1}$
}

\author{
*Correspondence: \\ canglong@issas.ac.cn \\ ${ }^{1}$ Key Laboratory of Soil \\ Environment and Pollution \\ Remediation, Institute of Soil \\ Science, Chinese Academy \\ of Sciences, Nanjing 210008, \\ China \\ Full list of author information \\ is available at the end of the \\ article
}

\begin{abstract}
The particle size of apatite is one of the critical factors that influence the adsorption of heavy metals on apatite in the remediation of heavy metal contaminated soils using apatite. However, little research has been done evaluating the impact of different particle sizes of apatite on immobilization remediation of heavy metal polluted soils in field. In this study, the adsorption isothermal experiments of copper on three kinds of apatite was tested, and the field experiment by using different particle sizes apatite [nanohydroxyapatite (NAP), micro-hydroxyapatite (MAP), ordinary particle apatite (OAP)] at a same dosage of $25.8 \mathrm{t} / \mathrm{ha}(1.16 \%$, W/W) was also conducted. Ryegrass was chosen as the test plant. The ryegrass biomass, the copper contents in ryegrass and the copper fractionations in soil were determined after field experiments. Results of adsorption experiments showed that the adsorption amounts of copper on OAP was the lowest among different particles. The adsorption amounts of copper on MAP was higher than NAP at high copper equilibrium concentration $\left(>1 \mathrm{mmol} \mathrm{L}^{-1}\right)$, an opposite trend was obtained at low copper concentration $\left(<1 \mathrm{mmol} \mathrm{L}^{-1}\right)$. In the field experiment, we found that the application of different apatites could effectively increase the soil $\mathrm{pH}$, decrease the available copper concentration in soil, provide more nutrient phosphate and promote the growth of ryegrass. The ryegrass biomass and the copper accumulation in ryegrass were the highest in MAP among all treatments. The effective order of apatite in phytoremediation of copper contaminated field soil was MAP $>$ NAP $>$ OAP, which was attributed to the high adsorption capacity of copper and the strong releasing of phosphate by MAP.
\end{abstract}

Keywords: Apatite, Particle size, Copper, Adsorption, Field experiment

\section{Background}

Soil contamination is an excess of any compound or element, which results in serious impact on ecosystems, groundwater, agricultural productivity and human health (Adriano 2001). Copper is an essential element: it forms organic complexes and metalloproteins, especially haemoglobin (Kos and Lestan 2004). But high concentration of Cu could cause serious harms to biota and human (Adrees et al. 2015). Therefore, effective amendment and proper treatment to decrease its availability and mobility become necessary.

Apatite is a common name for different minerals with the formula $\mathrm{X}_{5}\left(\mathrm{YO}_{4}\right)_{3}(\mathrm{OH}, \mathrm{F}, \mathrm{Cl})$, where $\mathrm{X}$ is divalent metal, such as $\mathrm{Ca}, \mathrm{Ba}, \mathrm{Pb}$, etc., and $\mathrm{Y}$ is phosphorous, possible replaced

(c) 2016 The Author(s). This article is distributed under the terms of the Creative Commons Attribution 4.0 International License (http://creativecommons.org/licenses/by/4.0/), which permits unrestricted use, distribution, and reproduction in any medium, provided you give appropriate credit to the original author(s) and the source, provide a link to the Creative Commons license, and indicate if changes were made. 
by other elements such as As, V, C (Narasaraju and Phebe 1996). Studies focusing on immobilization of heavy metals by apatite such as natural mineral phosphate and synthetic apatite have been extensively reported (Laperche et al. 1996; Ma et al. 1995; Miretzky and Fernandez-Cirelli 2008). Hydroxyapatite (HAP) is a member of apatite mineral family, with the formula $\mathrm{Ca}_{10}\left(\mathrm{PO}_{4}\right)_{6}(\mathrm{OH})_{2}$, and has a high adsorption capacity for divalent heavy metal ions and has been used for wastewater treatment (Corami et al. 2008; Ma et al. 1994; Sandrine et al. 2007; Smiciklas et al. 2006) and soil remediation (Chaturvedi et al. 2006; Keller et al. 2005). Metal ions such as $\mathrm{Pb}(\mathrm{II}), \mathrm{Cu}(\mathrm{II}), \mathrm{Co}(\mathrm{II}), \mathrm{Zn}(\mathrm{II})$, and $\mathrm{Cd}(\mathrm{II})$ are successfully immobilized by adsorption and precipitation on the surface of HAP (Corami et al. 2007; Lusvardi et al. 2002; Sandrine et al. 2007; Smiciklas et al. 2006). Moreover, Chen et al. (2006) indicated that the solubility and grain size of rock phosphate could affect the effectiveness of the amendment in in situ remediation technology, and they concluded that the rock phosphate with small grain size $(<35 \mu \mathrm{m})$ was superior to grain sizes larger than $35 \mu \mathrm{m}$ at reducing heavy metals uptake in plant. Sugiyama et al. (2002) found that the exchange capacity of apatite of particle size under $0.85 \mathrm{~mm}$ to $\mathrm{Pb}$ (II) is much better than that of particle size from 0.85 to $1.70 \mathrm{~mm}$. In particular, nano-materials represent a promising application in some areas due to their high surface areas, small sizes and special chemical reaction (Zhang et al. 2010). Wang et al. (2009) found that nanoscale HAP exhibits a strong adsorption for $\mathrm{Cu}$, and is a good adsorbent for immobilization of heavy metals. Liu and Zhao (2007) found nano-particles had better performance than normal particles during studying the immobilization of $\mathrm{Cu}(\mathrm{II})$ in soil using iron phosphate.

Although the immobilization of heavy metals using apatite has been proved successfully in the laboratory, the remediation of heavy metal contaminated soils by nanohydroxyapatite (NAP), micro-hydroxyapatite (MAP) and ordinary particle size of apatite (OAP) in the field is very limited. Thus, the objectives of this study were to evaluate the $\mathrm{Cu}$ adsorption capacity on different particle size of apatite (NAP, MAP, OAP) and the remediation ability of $\mathrm{Cu}$ contaminated soil by different apatites in the field condition.

\section{Methods}

\section{Soil}

The test site is located in Guixi city, Jiangxi province, China $\left(116^{\circ} 55^{\prime} \mathrm{E}, 28^{\circ} 12^{\prime} \mathrm{N}\right)$. This area is influenced by Southeast Asia Monsoon, so the climate is warm and humid. The soil was polluted by the sewage and waste gas from $\mathrm{Cu}$ smelting factory. The test field has been abandoned for many years and there are many serious phenomena such as desertification, acidification and heavy mental pollution. The soil $\mathrm{pH}$, organic matter content, available $\mathrm{N}$, $\mathrm{P}$ and $\mathrm{K}$ concentration were 4.25, $30.8 \mathrm{~g} \mathrm{~kg}^{-1}, 46.7,122$ and $41.5 \mathrm{mg} \mathrm{kg}^{-1}$, respectively. The total $\mathrm{Cu}, \mathrm{Zn}, \mathrm{Pb}$ and $\mathrm{Cd}$ concentrations were $580,85.5,37.6$ and $0.35 \mathrm{mg} \mathrm{kg}^{-1}$, respectively.

\section{Materials}

Nano-hydroxyapatite (NAP), micro-hydroxyapatite (MAP) and ordinary particle size of apatite (OAP) were used as adsorption materials and purchased from Nanjing emperor nano material Co. Ltd. and Xintai phosphorus chemical plant. The basic physicochemical properties and the TEM imaging of apatites are shown in Table 1 and Fig. 1. Ryegrass (Lolium perenne L.), supplied by Nanjing Shenzhou Seeds Industry Co., Ltd., was chose as the test plant. 


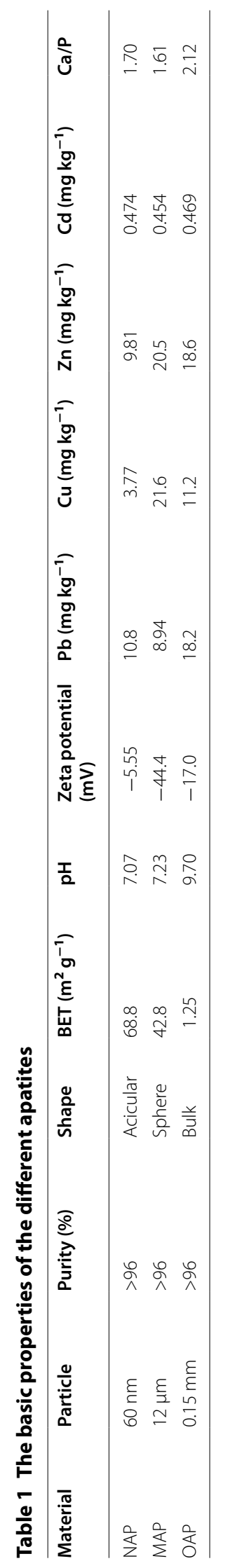



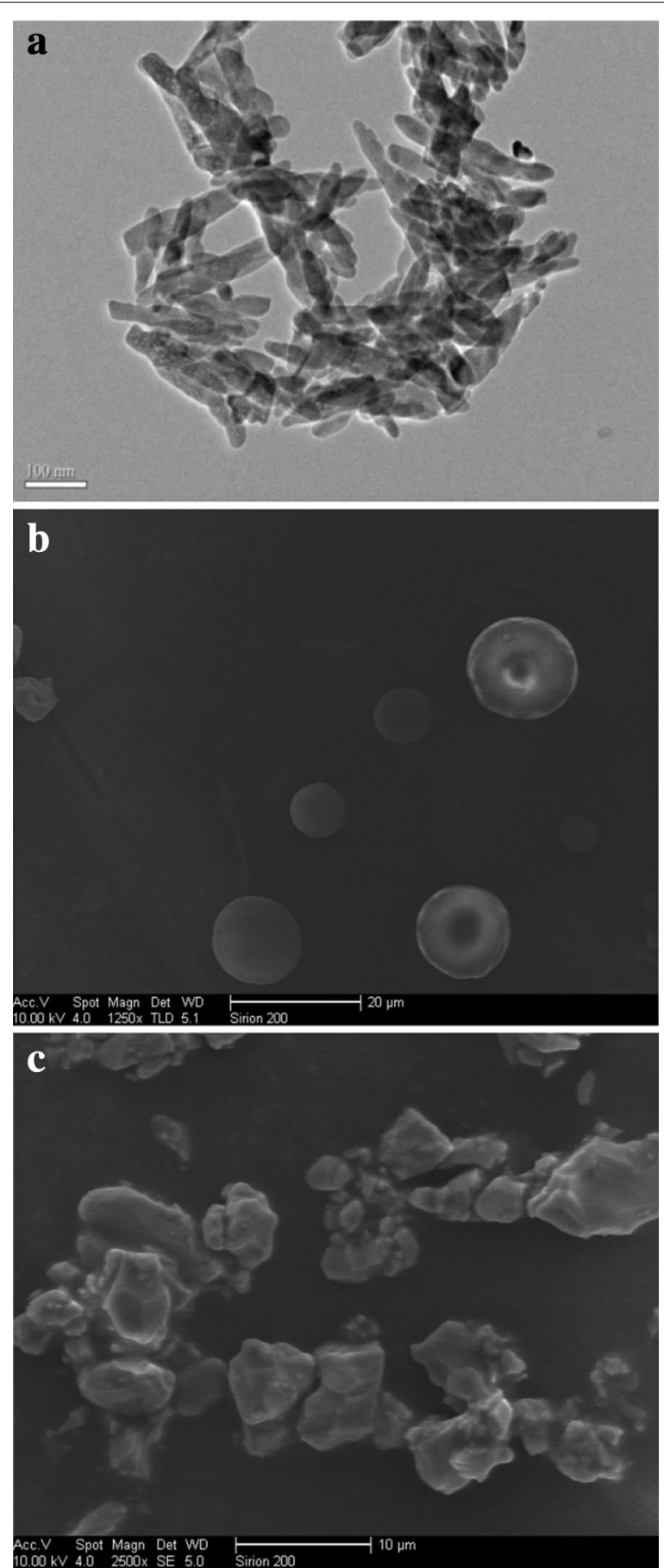

Fig. 1 The TEM images of different apatites. a nano-hydroxyapatite (NAP), b micro-hydroxyapatite (MAP), c ordinary particle size of apatite (OAP)

\section{Adsorption isothermal experiments}

The adsorption isothermal experiments were carried out in $50 \mathrm{~mL}$ polypropylene centrifugation tubes by mixing $0.05 \mathrm{~g}$ of different apatites with $25 \mathrm{~mL} 0.01 \mathrm{~mol} \mathrm{~L}^{-1}$ $\mathrm{NaNO}_{3}$ containing $25 \mathrm{mmol} \mathrm{L}{ }^{-1}$ MES (4-Morpholineethanesulfonic acid hydrate). The 
$\mathrm{pH}$ of suspensions were adjusted to 5.5 by diluted $\mathrm{HCl}$ or $\mathrm{NaOH}$. Afterwards, $5 \mathrm{~mL}$ of $0.01 \mathrm{~mol} \mathrm{~L}^{-1} \mathrm{NaNO}_{3}$ with different concentration of $\mathrm{Cu}\left(\mathrm{NO}_{3}\right)_{2}$ were added into the tubes. The initial concentration of copper in the solutions were $0,0.2,0.4,1.0,1.6,2.0$, 5.0 and $10.0 \mathrm{mmol} \mathrm{L}^{-1}$, respectively, and each treatment was duplicated. All samples were shaken for $24 \mathrm{~h}$ at $25{ }^{\circ} \mathrm{C}$, followed by centrifuging at $9000 \mathrm{rpm}$ for $15 \mathrm{~min}$. The supernatants were filtered through a $0.22 \mu \mathrm{m}$ Millipore filter. The $\mathrm{Cu}$ concentrations in the filtrate were measured by atomic absorption spectroscopy (AAS). Adsorbed copper was quantified by the difference between initial and final copper concentrations in solution after control correction. The adsorption isotherms were fitted by the Langmuir and Freundlich equations (Eqs. 1 and 2, respectively).

$$
\begin{aligned}
& \mathrm{Q}_{\mathrm{e}}=\mathrm{Q}_{\mathrm{m}} \mathrm{K}_{\mathrm{L}} \mathrm{C}_{\mathrm{e}} /\left(1+\mathrm{K}_{\mathrm{L}} \mathrm{C}_{\mathrm{e}}\right) \\
& \mathrm{Q}_{\mathrm{e}}=\mathrm{K}_{\mathrm{f}} \mathrm{Cn} \mathrm{e}
\end{aligned}
$$

where $C_{e}\left(\mathrm{mmol} \mathrm{L}^{-1}\right)$ is the equilibrium concentration of copper in solution, $\mathrm{Q}_{\mathrm{m}}$ $\left(\mathrm{mmol} \mathrm{kg}^{-1}\right)$ is the adsorbed quantity of copper, $\mathrm{Q}_{\mathrm{m}}\left(\mathrm{mmol} \mathrm{kg}^{-1}\right)$ and $\mathrm{K}_{\mathrm{L}}\left(\mathrm{L} \mathrm{kg}^{-1}\right)$ indicate the maximal monolayer adsorption capacity and a constant related to adsorption energy, respectively. $\mathrm{K}_{\mathrm{f}}$ and $\mathrm{n}$ are Freundlich constants giving an estimation of the adsorption capacity and intensity, respectively.

\section{Field experiment}

The field plot trials were conducted to investigate the remediation effect by using different particle size of apatite in the $\mathrm{Cu}$ contaminated field. Triplicated trial plots $(2 \mathrm{~m} \times 2 \mathrm{~m})$ were laid out by a randomized block design. The trial plots were separated by $0.5 \mathrm{~m}$ high PVC sheets with $0.2 \mathrm{~m}$ above ground and $0.3 \mathrm{~m}$ underground. The application dosages of the apatite were $1.16 \%(\mathrm{~W} / \mathrm{W})$ of the topsoil $(0-20 \mathrm{~cm})$ weight $\left(25.8\right.$ ton ha ${ }^{-1}$ ). The treatments were labeled as NAP, MAP, OAP and CK (without any amendment), respectively.

On November 13, 2010, the site was ploughed and harrowed. In order to avoid the suspension and agglomeration of apatites (especially NAP), the apatite powders were spread on the soil surface and mixed evenly with topsoil, then each plot was irrigated with $100 \mathrm{~L}$ of tap water. In each plot, $20 \mathrm{~g}$ of ryegrass seeds was sown and $0.5 \mathrm{~kg}$ of compound fertilizers (the total content of $\mathrm{N}, \mathrm{P}_{2} \mathrm{O}_{5}$ and $\mathrm{K}_{2} \mathrm{O}$ were $15 \%$ ) was applied. After 18 weeks (the first harvest, March 29, 2011) and 21 weeks (the second harvest, April 22, 2011) growing, the aboveground biomass of ryegrass was harvested, and then $0.04 \mathrm{~kg}$ of the urea was applied per plot. After 23 weeks of growth (the third harvest, May 8, 2011), the shoot and root of ryegrass were harvested, and the soil samples were also collected. The shoot samples was thoroughly washed by tap water and rinsed by deionized water. The root samples were thoroughly washed using a 2-step washing progress, which consisted of a first wash with EDTA $\left(20 \mathrm{mmol} \mathrm{L}^{-1}\right)$ and a second rinse with deionized water. Both shoot and root samples were preliminarily dried at $105{ }^{\circ} \mathrm{C}$ for $30 \mathrm{~min}$, and then switched to $70{ }^{\circ} \mathrm{C}$ until a constant weight has been reached (about $48 \mathrm{~h}$ ). The dry matters were grounded to fine powders using a mechanical grinder after the yields were recorded. The soil samples were air dried and sieved through 2 and $0.149 \mathrm{~mm}$ sieves before measurements. 


\section{Analytical methods}

The physical structures of different apatites were imaged by Transmission Electron Microscope (TEM, JEOL TEM-2100,Japan). The mineral phases were analyzed using X-ray Diffraction Spectrometer (XRD, Rigaku Ultima IV, Japan) with the diffraction pattern compared to the referenced XRD standard map (Joint Committee on Powder Diffraction and Standards, NO 09-0432). The FTIR spectra was record on a Nicolet 380 patterns (USA) of the solid were taken (scan in $400-4000 \mathrm{~cm}^{-1}$ ), as about $2 \mathrm{mg} \mathrm{sam}$ ples were suspended in about $150 \mathrm{mg}$ of $\mathrm{KBr}$. Zeta potential was determined by NanoBrook 90Plus PLAS (Brookhaven Instruments, America). The specific surface area was measured by the Brunauer-Emmett-Teller (BET) method using the specific surface area automatic analyzer (Quantachrome Autosorb-iQ, America). The $\mathrm{pH}$ of apatites were measured in suspension with the carbon dioxide-free distilled water to solid ratio of 1:6 (W/V) by using pH meter (pHS-2B, Shanghai Rex Electric Chemical Co. Ltd., China). The apatites were digested using $\mathrm{HNO}_{3}-\mathrm{HF}-\mathrm{HClO}_{4}(10: 10: 1, \mathrm{~V} / \mathrm{V})$ mixture and the digestion solutions were analyzed to quantify the concentrations of $\mathrm{Cu}, \mathrm{Zn}, \mathrm{Pb}, \mathrm{Cd}, \mathrm{Ca}$ and $\mathrm{P}$ in apatites using a flame atomic absorption spectrophotometer (Hitachi Z-2000, Japan).

Soil $\mathrm{pH}$, organic matter content and available phosphorus contents were analyzed based on the method given by $\mathrm{Lu}(2000)$. The soil $\mathrm{pH}$ were measured in suspension with the carbon dioxide-free distilled water to soil ratio of 2.5 (V/W) by pH meter (pHS-2B). Soil organic matter content was analyzed by dichromate oxidation method. Available soil phosphorus was extracted by the mixed solution contained $0.03 \mathrm{~mol} \mathrm{~L}^{-1} \mathrm{NH}_{4} \mathrm{~F}$ and $0.025 \mathrm{~mol} \mathrm{~L}^{-1} \mathrm{HCl}$ and determined by ICP (PerkinElmer Optima 8000).

To determine the total concentration of metals in soil, the soil samples were passed through $0.149 \mathrm{~mm}$ pore-size sieve and dried at $105{ }^{\circ} \mathrm{C}$ for $4 \mathrm{~h}$, and then digested in an $\mathrm{HNO}_{3}-\mathrm{HF}-\mathrm{HClO}_{4}(10: 10: 1, \mathrm{~V} / \mathrm{V})$ mixture. Blank and soil standard materials (GBW07401 and GBW-07406) (China National Center for Standard Material) were used for quality control. The $\mathrm{Cu}$ fractions were identified by the BCR sequential extraction method from the European Community Bureau of Reference (Rauret et al. 2000), and the acid soluble, reducible, oxidizable, and reducible fractions of $\mathrm{Cu}$ were extracted by $0.11 \mathrm{~mol} \mathrm{~L}^{-1}$ acetic acid, $0.1 \mathrm{~mol} \mathrm{~L}^{-1}$ hydroxylamine hydrochloride $(\mathrm{pH} 2), 30 \% \mathrm{~W} / \mathrm{V}$ $\mathrm{H}_{2} \mathrm{O}_{2}$ and $1 \mathrm{~mol} \mathrm{~L}^{-1} \mathrm{NH}_{4} \mathrm{OAc}\left(\mathrm{pH}\right.$ 2), $\mathrm{HNO}_{3}-\mathrm{HF}-\mathrm{HClO}_{4}(1: 2: 1, \mathrm{~V} / \mathrm{V})$, respectively. The recovery of total $\mathrm{Cu}$ concentration was controlled in $90-110 \%$. TCLP (Toxicity Characteristic Leaching Procedure) method was used to estimate the variation of $\mathrm{Cu}$ toxicity in amended soils. This procedure diluted a $5.7 \mathrm{~mL}$ glacial acetic acid in $1 \mathrm{~L}$ deionized water and used $20 \mathrm{~mL}$ of this solution ( $\mathrm{pH} 2.88$ ) to extract copper from the $1 \mathrm{~g}$ of soil samples (Sun et al. 2006).

For the $\mathrm{Cu}$ concentration in ryegrass shoots and roots, about $0.5 \mathrm{~g}$ sample was weighed in a $50 \mathrm{~mL}$ triangular flask with mixture of $\mathrm{HNO}_{3}(20 \mathrm{~mL})$ and $\mathrm{H}_{2} \mathrm{O}_{2}(4 \mathrm{~mL})$ and left at room temperature overnight. Then, the samples were digested on an electric heating plate $\left(120-180^{\circ} \mathrm{C}\right)$. Blank and standard reference materials (GBW-10015 and GBW10010) (spinach leaves and rice grain, China National Center for Standard Material) were used for quality control in the digestion and analysis processes. The $\mathrm{Cu}$ concentrations of in digestion solutions were analyzed using a flame atomic absorption spectrophotometer (Hitachi Z-2000, Japan). 


\section{Statistical analysis}

SPSS 18.0 and Excel 2003 were used for statistical analysis. Langmuir and Freundlich equations were applied to fit the copper adsorption isothermals. The results of field experiments were subjected to analysis by one-way analysis of variance (ANOVA) followed by Duncan multiple comparisons $(p<0.5)$ using SPSS 18.0.

\section{Results and discussion}

\section{Characteristics of different apatites}

TEM images (Fig. 1) showed that the shapes of NAP, MAP and OAP were acicular, sphere and bulk, respectively. The order of particle size of different apatite was NAP < MAP < OAP, which was on the opposite trend with the specific surface area by the BET method. The results of XRD analysis showed NAP and MAP consisted with the standard card of hydroxyapatite (JCPDS 9-432), and fluorapatite (65\%) was found as the primarily mineral in OAP, and the second most abundant mineral was dolomite (30\%), followed by hydromica ( $2 \%)$, talcum (2\%) and kaolinite (1\%) (Fig. 2). The XRD and FTIR spectrograms (Figs. 2, 3) indicated the OAP is not pure apatite. Some other minerals (dolomite, hydromica, etc.) didn't contain phosphorus, which decreased the phosphorus content in OAP and increased the $\mathrm{Ca} / \mathrm{P}$ ratio of OAP to 2.12 . The $\mathrm{Ca} / \mathrm{P}$ molar ratio of NAP and MAP were 1.70 and 1.61, respectively, which is close to the ideal ratio of 1.67 .

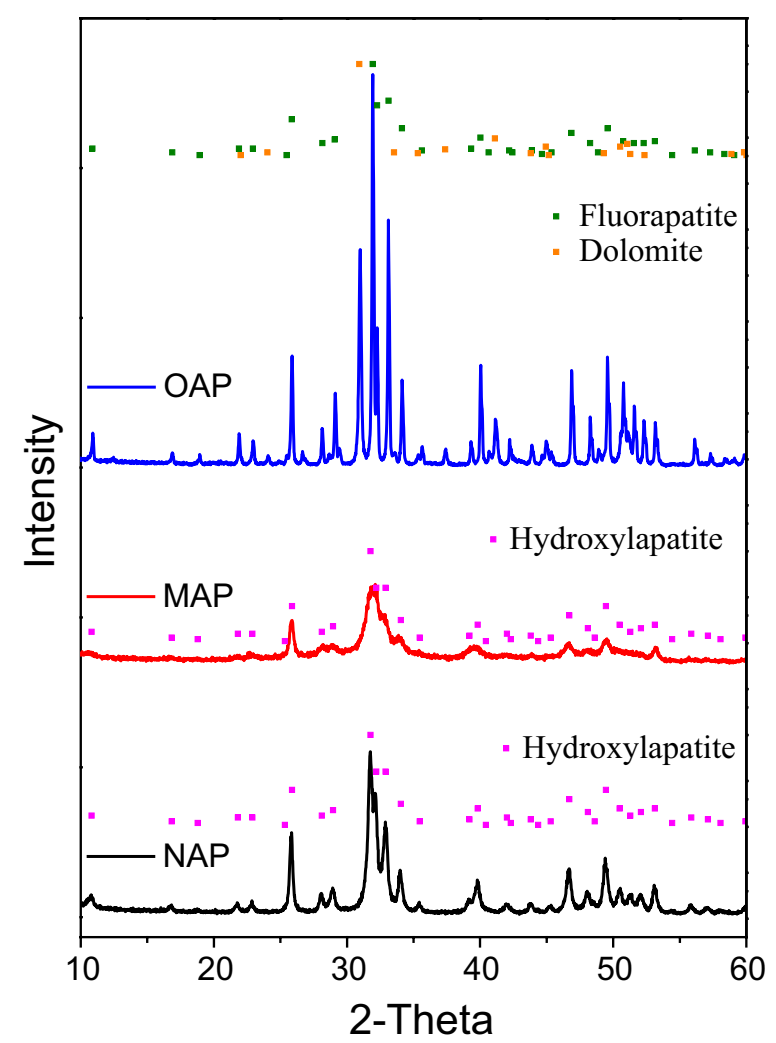

Fig. 2 X-ray diffraction (XRD) pattern of different apatites 


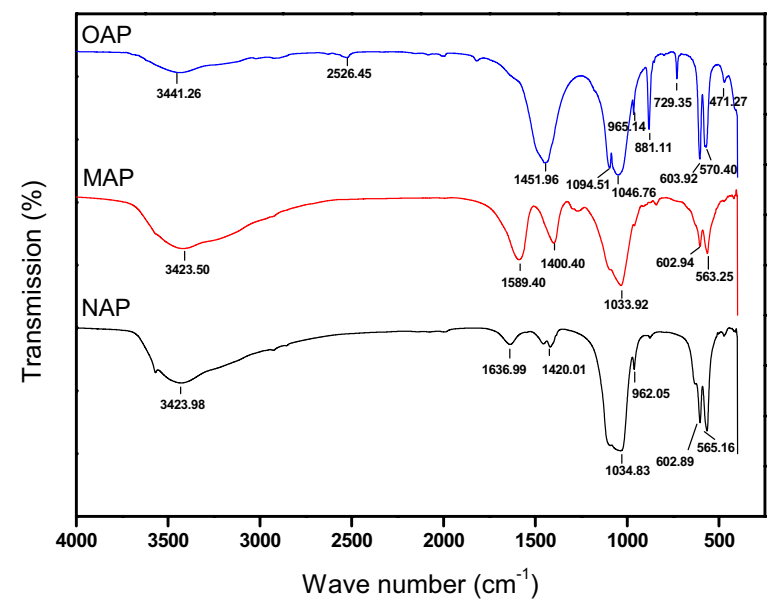

Fig. 3 Fourier transform infrared spectroscopy (FTIR) spectra of different apatites

Zeta potential of MAP was $-44.4 \mathrm{mV}$ and higher than NAP and OAP (absolute value), which indicated that MAP preferentially disperses in soil and mixes with soil components compare to NAP and OAP. The concentrations of heavy metal in apatite were 3.77-21.6 mg kg${ }^{-1}$ for $\mathrm{Cu}, 9.81-20.5 \mathrm{mg} \mathrm{kg}^{-1}$ for $\mathrm{Zn}, 8.94-18.2 \mathrm{mg} \mathrm{kg}^{-1}$ for $\mathrm{Pb}$ and $0.454-0.474 \mathrm{mg} \mathrm{kg}^{-1}$ for $\mathrm{Cd}$, respectively, and slightly higher than the concentration previously reported (Cui et al. 2013, 2014).

\section{Adsorption of $\mathrm{Cu}$ on different apatites}

Adsorption isotherms of $\mathrm{Cu}$ on apatites at $\mathrm{pH} 5.5$ are given in Fig. 4. The adsorption of $\mathrm{Cu}$ on apatite gradually increased with the increase of copper concentration in the equilibrium solution, which is in agreement with those reported by Wang et al. (2009) and Cui et al. (2014). Figure 4a show the adsorption of $\mathrm{Cu}$ in $\mathrm{mmol} \mathrm{kg}^{-1}$. In case of lower $\mathrm{Cu}$ concentration (below $1.0 \mathrm{mmol} \mathrm{L}^{-1}$ ) in equilibrium solution, the adsorption trend (from high to low capacity) of apatites was NAP > MAP > OAP. The adsorption trend was similar to the study given by Ma et al. (1995), in which it has been suggested that for phosphate rock, higher specific surface area increased its dissolution rate and promoted the adsorption and immobilization of heavy metals. The adsorptions of $\mathrm{Cu}$ were showed in $\mathrm{mmol} \mathrm{m}^{-2}$ in Fig. $4 \mathrm{~b}$. The $\mathrm{Cu}$ adsorption on NAP and MAP were similar with the result in Fig. 4a. That suggested that NAP displayed higher immobilizing effect than MAP due to its high surface area (Table 1). However, there was different between Fig. 4a, $\mathrm{b}$ for the $\mathrm{Cu}$ adsorption capacity on OAP, which indicated the composition and purity of OAP affected the $\mathrm{Cu}$ adsorption on OAP.

However, an interesting phenomenon was observed that the $\mathrm{Cu}$ adsorption capacity on MAP increased rapidly and was higher than that on NAP when the equilibrium concentration of $\mathrm{Cu}$ exceeded $1.0 \mathrm{mmol} \mathrm{L}^{-1}$ (Fig. 4a). The highest $\mathrm{Cu}$ adsorption capacity on NAP and MAP were $800,2300 \mathrm{mmol} \mathrm{kg}^{-1}$, respectively, and the adsorption capacity on OAP kept staying at a very low level (below $214 \mathrm{mmol} \mathrm{kg}^{-1}$ ). The parameters for Langmuir and Freundlich fitting are listed in Table 2, the adsorption isotherms of MAP and OAP in $0-10 \mathrm{mmol} \mathrm{L}^{-1}$ were not fitted by Langmuir and Freundlich models and OAP in $0-1 \mathrm{mmol} \mathrm{L}^{-1}$ was not fitted by Langmuir model. Cheung et al. (2002) found that 

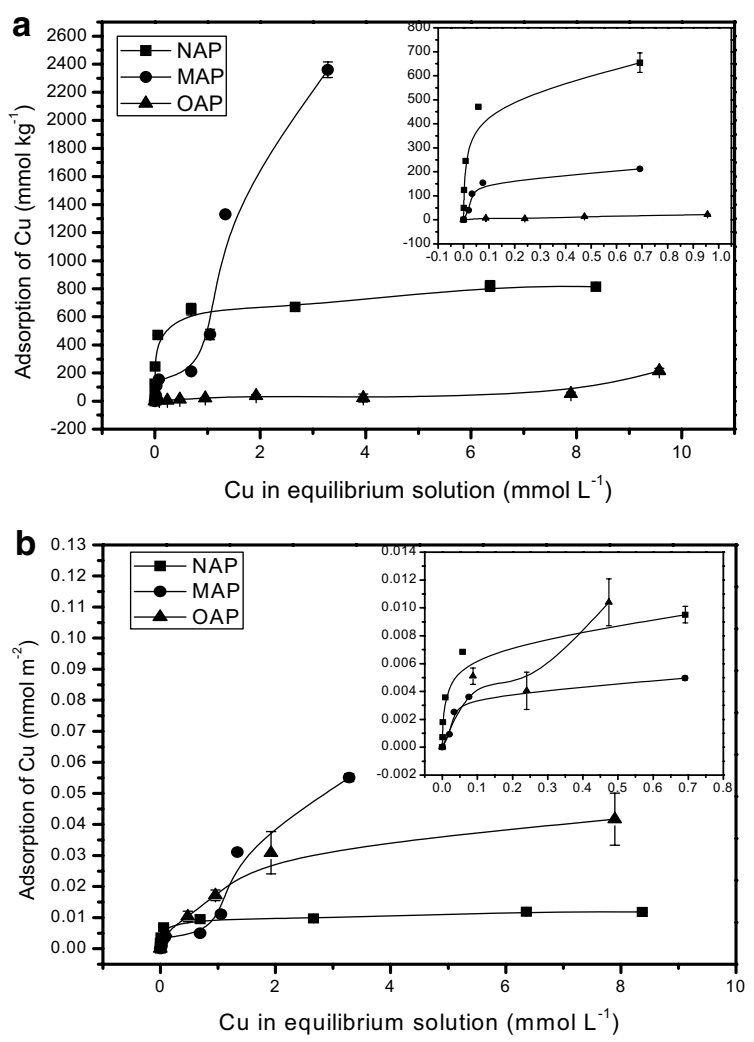

Fig. 4 Adsorption isotherms of $\mathrm{Cu}$ on the three kinds of apatite at pH 5.5 (The unit of $\mathrm{Cu}$ absorption amount in $y$-axis were expressed by $\mathrm{mmol} \mathrm{kg}^{-1}(\mathbf{a})$ and $\mathrm{mmol} \mathrm{m}^{-2}(\mathbf{b})$, respectively)

Table 2 Langmuir and Freundlich model parameters of different apatite at pH 5.5

\begin{tabular}{|c|c|c|c|c|c|c|c|c|c|}
\hline \multirow[t]{2}{*}{$\mathrm{Ce}\left(\mathrm{mmol} \mathrm{L}^{-1}\right)$} & \multirow[t]{2}{*}{ Material } & \multicolumn{4}{|c|}{ Langmuir } & \multicolumn{4}{|c|}{ Freundlich } \\
\hline & & $\mathrm{K}_{\mathrm{L}}$ & $Q_{m}$ & $\mathrm{R}^{2}$ & $P$ & $\mathrm{~K}_{\mathrm{F}}$ & $1 / n$ & $\mathrm{R}^{2}$ & $\mathbf{P}$ \\
\hline 0-10 & NAP & 43.15 & 742.9 & 0.9628 & $<0.05$ & 592.1 & 0.1751 & 0.9500 & $<0.01$ \\
\hline $0-1$ & NAP & 72.73 & 637.7 & 0.9815 & $<0.05$ & 752.9 & 0.2439 & 0.9480 & $<0.01$ \\
\hline $0-1$ & MAP & 20.84 & 232.4 & 0.9616 & $<0.05$ & 243.6 & 0.2739 & 0.8882 & $<0.05$ \\
\hline $0-1$ & OAP & - & - & - & - & 22.03 & 0.7455 & 0.9460 & $<0.05$ \\
\hline
\end{tabular}

The adsorption isotherms of MAP and OAP in $0-10 \mathrm{mmol} \mathrm{L}^{-1}$ were not fitted by Langmuir and Freundlich models and OAP in $0-1 \mathrm{mmol} \mathrm{L}^{-1}$ were not fitted by Langmuir models, so their model parameters are not listed

Langmuir equation can used to describe the sorption of $\mathrm{Cu}$ by bone char $(500-710 \mu \mathrm{m}$ particle size) mainly composed with hydroxyapatite. This difference might be due to that the different composition and property of sorbent and experiment conditions. The adsorption isotherms of NAP were well fitted by Langmuir and Freundlich models, and the correlation coefficient $\left(\mathrm{R}^{2}\right)$ were $0.96\left(0-10 \mathrm{mmol} \mathrm{L}^{-1}\right)$ and $0.98\left(0-1 \mathrm{mmol} \mathrm{L}^{-1}\right)$ in Langmuir models and $0.95\left(0-10 \mathrm{mmol} \mathrm{L}^{-1}\right)$ and $0.94\left(0-1 \mathrm{mmol} \mathrm{L}^{-1}\right)$ in Freundlich models, respectively. These results showed that the Langmuir models is better in describing the $\mathrm{Cu}$ adsorption behavior on NAP and the adsorption behavior was mainly a monomolecular adsorption process, similar to studies given by Chen et al. (2010) and Wang et al. (2009). Adsorption reaction of $\mathrm{Cu}$ on MAP is divided into two phases (Fig. 2): first, the sorption of $\mathrm{Cu}$ on MAP corresponds basically to Langmuir equation at 
low $\mathrm{Cu}$ equilibrium concentration $\left(<1.0 \mathrm{mmol} \mathrm{L}^{-1}\right)$; second, the adsorption became linear with both rate and capacity increased linearly at high $\mathrm{Cu}$ equilibrium concentration $\left(>1.0 \mathrm{mmol} \mathrm{L}^{-1}\right)$. These indicated that the adsorption of $\mathrm{Cu}$ on MAP might be a multilayer adsorption and the surface of MAP had a strong affinity of $\mathrm{Cu}$ at higher $\mathrm{Cu}$ concentration. The best metal sorption on apatites need poor crystallinity (Chen et al. 1997a, b). XRD analysis showed the crystallinity of MAP was the poorest, so the $\mathrm{Cu}$ adsorption capacity on MAP was the best.

\section{Effect of different apatites on soil pH, TCLP extracted Cu concentrations}

The addition of NAP, MAP and OAP led to the increase of soil pH (Fig. 5A), which is similar with previous reports (Chlopecka and Adriano 1996; Ma et al. 1995) and probably due to the hydroxyl, calcium and some other basic groups of apatite (Boisson et al. 1999; Knox et al. 2003). However, the soil $\mathrm{pH}$ of different treatments significantly increased in March 2011, and then a decrease of soil pH was observed in May 2011. Similarly, Cui et al. (2014) found that with the application of apatite, soil pH significantly increased after 1 year and decreased after 4 years. They speculated that it might be attributed to the fact that test site was located in an acid deposition zone. As shown in Fig. 5A, the soil pH followed the same order of OAP > MAP > NAP > CK in March 2011 and May 2011, which was consisted with the $\mathrm{pH}$ order of apatites (OAP > MAP > NAP). Moreover, the soil $\mathrm{pH}$ treated by NAP slightly changed whereas significant $\mathrm{pH}$ increases
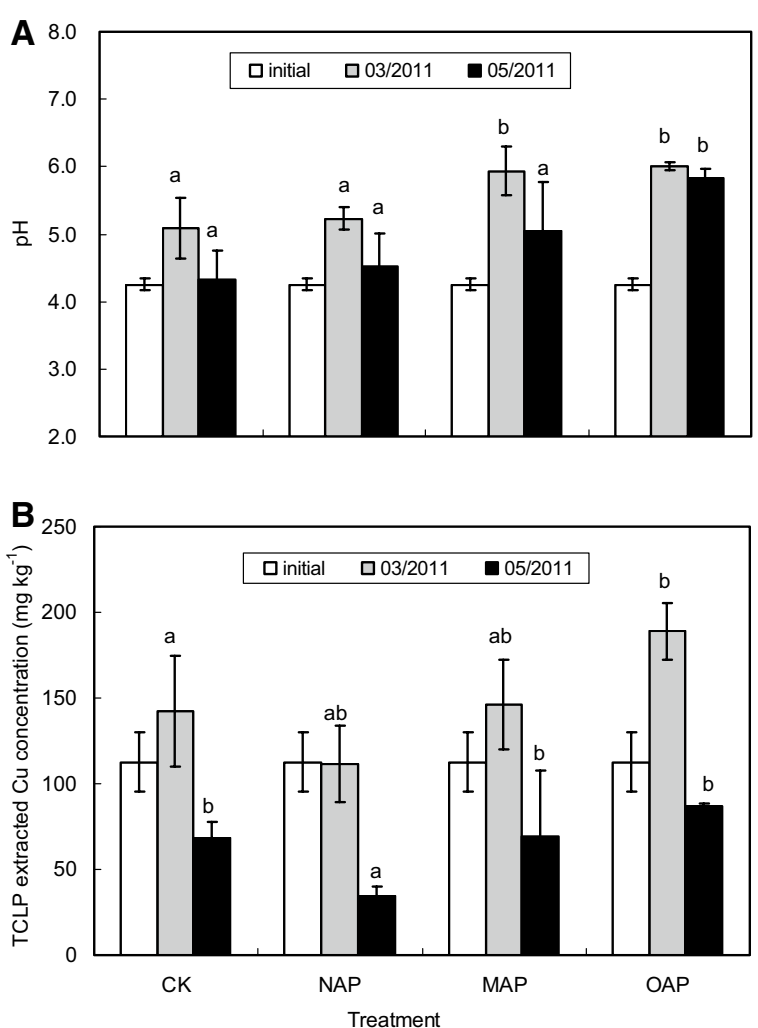

Fig. 5 Effect of different apatites on soil pH (A) and TCLP extracted Cu concentrations (B) (different letters indicated significant differences between treatments at the same time $(p<0.05)$ 
were identified in soil treated by OAP and MAP. This indicated that OAP and MAP is more effective in increasing soil $\mathrm{pH}$ than NAP under the identical condition.

Figure 5B shows the concentration changes of TCLP extracted $\mathrm{Cu}$ caused by the addition of NAP, MAP and OAP, and the concentration increased in March 2011 compared to November 2010. Possibly due to the open experimental system in field, the immobilization process of $\mathrm{Cu}$ was relatively slow. But after two months since March 2011, TCLP extracted $\mathrm{Cu}$ decreased significantly alone with the order of $\mathrm{OAP}>\mathrm{CK}>\mathrm{MAP}>\mathrm{NAP}$. The results indicated that NAP and MAP were able to immobilize TCLP extracted $\mathrm{Cu}$ and NAP was more effective than MAP. However the soil $\mathrm{pH}$ in MAP treatment were higher than those in NAP treatment, especially there was significant differences between NAP and MAP in March 2011 (Fig. 5A). The immobilization of Cu by HAP was possibly more dependent on the high adsorption quantity of $\mathrm{Cu}$ rather than the soil $\mathrm{pH}$ comparing to that by MAP. Nevertheless, more experiments are still needed to further study the effect of soil $\mathrm{pH}$ on the immobilization mechanism of $\mathrm{Cu}$ by apatite.

\section{Effect of different apatites on the Cu speciation in soil}

The mobility of heavy metals, their bioavailability and related eco-toxicity to plant, depend strongly on their specific chemical fractions (Chen et al. 2014; Wang et al. 2012). Application of amendment can change the chemical fractions of heavy metals in soil and reduce their toxicity (Mackie et al. 2015; Montenegro et al. 2015; Rodriguez-Vila et al. 2015).

The concentration of $\mathrm{Cu}$ and the percentages of four fractions in soil estimated by BCR method are shown in Table 3. In the untreated soil (CK), the acid soluble fraction (250 mg/kg, $47.7 \%$ ) was predominant followed by reducible fraction $(134 \mathrm{mg} / \mathrm{kg}, 25.5 \%)$ and oxidizable fraction $(109 \mathrm{mg} / \mathrm{kg}, 20.7 \%)$, the lowest percentage was found in residual fraction $(31.9 \mathrm{mg} / \mathrm{kg}, 6.08 \%)$. After application of NAP, MAP and OAP, the Cu concentration in acid soluble fraction decreased significantly from $47.7 \%$ (CK) to $31.2 \%$ (NAP), $39.6 \%$ (MAP) and $40.5 \%$ (OAP), respectively. By contrast, the $\mathrm{Cu}$ concentration in reducible fraction increased significantly with the highest increasing in the NAP treatment and the lowest increasing in the OAP treatment. Only small changes in residual fraction were identified among all treatments. The results indicated that the application of apatites reduced the availability of $\mathrm{Cu}$ and attenuated its risk by decreasing the high toxic and mobile acid soluble fraction and meanwhile immobilizing $\mathrm{Cu}$ to relatively stable reducible and oxidizable fraction. The order of immobilizing is: NAP > MAP > OAP, but there have no significant difference in the acid soluble fraction between NAP and

Table 3 Effect of different apatites on the Cu fractionations in soil

\begin{tabular}{|c|c|c|c|c|c|c|c|c|c|}
\hline \multirow[t]{2}{*}{ Treatment } & \multicolumn{2}{|l|}{$\mathrm{F} 1$} & \multicolumn{2}{|l|}{ F2 } & \multicolumn{2}{|l|}{ F3 } & \multicolumn{2}{|l|}{ F4 } & \multirow{2}{*}{$\begin{array}{l}\text { Recovery } \\
\%\end{array}$} \\
\hline & $\mathrm{mg} \mathrm{kg}^{-1}$ & $\%$ & $\mathrm{mg} \mathrm{kg}^{-1}$ & $\%$ & $\mathrm{mg} \mathrm{kg}^{-1}$ & $\%$ & $\mathrm{mg} \mathrm{kg}^{-1}$ & $\%$ & \\
\hline CK & $250 \mathrm{a}$ & 47.7 & $134 \mathrm{C}$ & 25.5 & $109 c$ & 20.7 & $31.9 \mathrm{a}$ & 6.08 & 93.7 \\
\hline NAP & 195 a & 31.2 & $218 a$ & 34.8 & $180 \mathrm{a}$ & 28.6 & $33.5 \mathrm{a}$ & 5.34 & 110 \\
\hline MAP & $234 \mathrm{a}$ & 39.6 & 164 bc & 27.8 & 152 bc & 25.7 & $41.0 \mathrm{a}$ & 6.92 & 106 \\
\hline OAP & $244 a$ & 40.5 & $155 b c$ & 25.7 & $173 a b$ & 28.7 & $30.0 \mathrm{a}$ & 4.99 & 99.1 \\
\hline
\end{tabular}

F1, acid soluble fraction; F2, reducible fraction; F3, oxidizable fraction; F4, residual fraction; Mean values followed by different lowercase letters in each column means significantly different $(p<0.05, \mathrm{n}=3)$ 
MAP. A previous study (Cui et al. 2013) showed that MAP was more effective than NAP in immobilizing $\mathrm{Cu}$ under the greenhouse condition. The difference might be due to the physic-chemical properties of apatites and experiment conditions (pot or field experiment). The particle size of NAP ( $40 \mathrm{~nm})$ and MAP $(3 \mu \mathrm{m})$ in Cui's article (Cui et al. 2013) is smaller than that in our study ( $60 \mathrm{~nm}$ NAP and $12 \mu \mathrm{m}$ MAP), which could cause a bad dispersibility for NAP in soil and subsequently weak the immobilization effect. Nevertheless, more studies are needed to verify the different immobilization mechanisms of $\mathrm{Cu}$ by NAP and MAP under different conditions.

Possible mechanisms of metal retention by apatite included: (1) ion exchange at the surface of apatite (Xu et al. 1994); (2) surface complexation (Cao et al. 2004); (3) precipitation of some amorphous to poorly crystalline, mixed metal phosphates; and (4) substitution of $\mathrm{Ca}$ in apatite by other metals during recrystallization (or coprecipitation) (Chen et al. 1997a, b; Xu et al. 1994). According to the report of Lindsay (2001), the structure of hydroxyapatite is similar to that of fluorapatite, $\mathrm{F}^{-}$occupying the $\mathrm{OH}^{-}$ sites on the sixfold axis. But hydroxyapatite $(\log K=14.46)$ has a higher solubility than fluorapatite ( $\log \mathrm{K}=-0.21$ ). Ma et al. (1995) attributed that the higher Pb removal efficiency to higher solubility and purity of hydroxyapatite than phosphate rocks. Drouet (2015) indicated that Gibbs free energy also estimated the solubility of apatites. Moreover, Kaludjerovic-Radoicica and Raicevicb (2010) suggested that the $\Delta G^{0}$ of HAP was greater than that for LA (fluorapatite), and HAP showed a larger affinity for $\mathrm{Pb}$ removal by the greater value of the sorption capacity. In this study, the immobilizing capacity of $\mathrm{Cu}$ followed the order of NAP > MAP > OAP, and the OAP was primarily fluorapatite and not pure. Therefore, one possibility reason could be the higher solubility of MAP and NAP than OAP. Furthermore, larger specific surface areas were determined for NAP and MAP than OAP (Table 1), which is likely enhancing the sorption of metals and leading to the decrease of the bioavailability of metal (Chen et al. 2006; Zhang et al. 2010). Thermodynamic properties might be different somewhat depending on the grain size of the apatite (Drouet 2015), therefore, more studies about thermodynamic of NAP and MAP need to conduct.

\section{Effect of different apatites on ryegrass biomass}

Table 4 shows the shoot and root biomass of ryegrass in different treatments. Ryegrass was not able to grow in the CK treatment (without the addition of amendment), but application apatites resulted in improved the growth of ryegrass.

In general, the best growth responses (shoot and root) were observed at MAP addition among all treatments. And there were significant differences between this treatment and

Table 4 Effect of different apatites on the biomass of ryegrass

\begin{tabular}{lllllll}
\hline Treatment & \multicolumn{2}{l}{ Biomass of shoot $(\mathbf{g})$} & & $\begin{array}{l}\text { Biomass } \\
\text { of root (g) }\end{array}$ & $\begin{array}{l}\text { Total biomass } \\
\text { of shoot (g) }\end{array}$ & $\begin{array}{l}\text { Total biomass } \\
\text { of ryegrass (g) }\end{array}$ \\
\cline { 2 - 5 } & 1st cutting & 2nd cutting & 3rd cutting & & & \\
\hline NAP & $314.5 \mathrm{~b}$ & $670.7 \mathrm{~b}$ & $343.1 \mathrm{~b}$ & $232.9 \mathrm{~b}$ & $1328 \mathrm{~b}$ & $1561 \mathrm{~b}$ \\
MAP & $2808 \mathrm{a}$ & $1819 \mathrm{a}$ & $1075 \mathrm{a}$ & $501.3 \mathrm{a}$ & $5703 \mathrm{a}$ & $6205 \mathrm{a}$ \\
OAP & $356.3 \mathrm{~b}$ & $685.0 \mathrm{c}$ & $240.6 \mathrm{~b}$ & $159.2 \mathrm{bc}$ & $1282 \mathrm{~b}$ & $1441 \mathrm{~b}$ \\
\hline
\end{tabular}

Mean values followed by different lowercase letters in each column means significantly different $(p<0.05, \mathrm{n}=3)$ 
others. The trend of shoot, root and total biomass of ryegrass was MAP > NAP > OAP, although there was no significant difference between NAP and OAP. It is well known that nutrient availability is of primary importance to the productivity. It can be seen from Fig. 6 that the apatites significantly increased the concentration of available phosphorus and the increasing order was MAP > NAP > OAP, especially there have significant difference between MAP and NAP in May 2011. Therefore, the release of phosphorus by these different apatites was one of the important factors to the biomass variation. The $\mathrm{Cu}$ adsorption on NAP was higher than that on OAP (Fig. 4), but no significant difference of ryegrass biomass was found between NAP and OAP. So another important factor of ryegrass growth was the soil $\mathrm{pH}, 5.83-6.01$ in the OAP treatment, significantly higher than the soil pH (4.53-5.23) in the NAP treatment (Fig. 5). The neutral soil pH was beneficial to the growth of ryegrass (Mora et al. 2005; Rosas et al. 2007).

\section{Effect of different apatites on the Cu content and accumulation in ryegrass}

Table 5 shows the $\mathrm{Cu}$ content and accumulation in ryegrass of different treatments. After applying apatites with different particle sizes, the $\mathrm{Cu}$ contents in the shoot of different cutting time was different. The $\mathrm{Cu}$ contents in shoot after the first cutting was much higher than those of the second and the third cutting excepted for the NAP treatment, which may be related to the dilution effect resulting from the significantly increasing of ryegrass biomass in the second and the third cutting. There was no significant

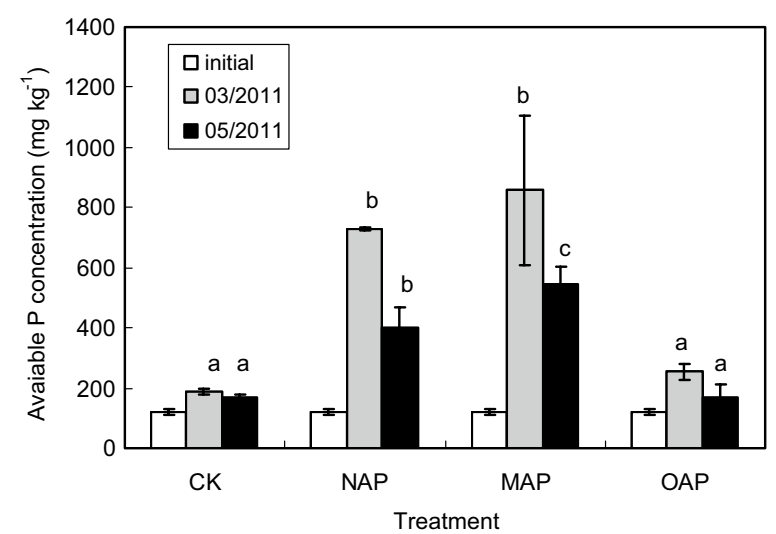

Fig. 6 Effect of different apatites on available phosphorus concentration [different letters indicated significant differences between treatments at the same time $(p<0.05)]$

Table 5 Effect of different apatites on $\mathrm{Cu}$ concentration and $\mathrm{Cu}$ accumulation in ryegrass

\begin{tabular}{|c|c|c|c|c|c|c|}
\hline \multirow[t]{3}{*}{ Treatment } & \multicolumn{4}{|c|}{$\mathrm{Cu}$ concentration $\left(\mathrm{mg} \mathrm{kg}^{-1}\right)$} & \multicolumn{2}{|c|}{$\begin{array}{l}\text { Cu accumulation } \\
\left(\mathrm{mg} \mathrm{plot}^{-1}\right)\end{array}$} \\
\hline & \multicolumn{3}{|l|}{ Shoot } & \multirow[t]{2}{*}{ Root } & \multirow[t]{2}{*}{ Shoot } & \multirow[t]{2}{*}{ Root } \\
\hline & 1 st cutting & 2 nd cutting & 3rd cutting & & & \\
\hline NAP & $182.3 \mathrm{a}$ & $91.6 \mathrm{a}$ & $124.3 \mathrm{a}$ & $7373 a b$ & $221.4 b$ & $1952 \mathrm{ab}$ \\
\hline MAP & $249.3 \mathrm{a}$ & $154.6 \mathrm{a}$ & $63.20 \mathrm{~b}$ & $12449 a$ & $1143 a$ & $5580 \mathrm{a}$ \\
\hline OAP & $235.7 \mathrm{a}$ & $178.9 \mathrm{a}$ & $128.1 \mathrm{a}$ & $3190 \mathrm{~b}$ & $206.1 \mathrm{~b}$ & $518.4 b$ \\
\hline
\end{tabular}

Mean values followed by different lowercase letters in each column means significantly different $(p<0.05, \mathrm{n}=3)$ 
difference of $\mathrm{Cu}$ contents in the shoot among different treatments, except that the $\mathrm{Cu}$ content in the third cutting shoot of the MAP treatment was significantly less than those in other treatments. However, the $\mathrm{Cu}$ content of root in the MAP was the highest in all treatments, and was about 1.69, 3.90 times that in NAP, OAP, respectively. According to the report of Laperche et al. (1997), the treatments with high quantities of phosphorus added resulted in the content of $\mathrm{Pb}$ in the plant roots the same or higher than the untreated soil. Therefore, we speculated that the higher $\mathrm{Cu}$ content of root in the MAP may be attributed to its highest phosphorus concentration (Fig. 6).

The $\mathrm{Cu}$ accumulation amount in shoot (1143 $\left.\mathrm{mg} \mathrm{plot}^{-1}\right)$ and root (5580 $\mathrm{mg} \mathrm{plot}^{-1}$ ) in the MAP treatment were 5.16 and 2.86 times higher than that in the NAP treatment, from which it was concluded that the ryegrass combined MAP was more effective than NAP or OAP in removing $\mathrm{Cu}$ from soil. The overall trend of $\mathrm{Cu}$ accumulation was MAP > NAP > OAP, which was corresponding to the ryegrass biomass. This field study indicated that the ryegrass biomass was the major factor for $\mathrm{Cu}$ accumulation, whereas the different particle size of apatite had small effect on the $\mathrm{Cu}$ content in the shoot of ryegrass.

\section{Conclusions}

Our study clearly showed that apatites effectively increased the soil $\mathrm{pH}$ and improved the growth of ryegrass, decreased the concentration of available $\mathrm{Cu}$ in soil, and promoted the $\mathrm{Cu}$ transformation from active to stable fraction in field experiment. Although the specific surface area of NAP was larger than MAP and OAP, the adsorption of $\mathrm{Cu}$ on MAP was better than that on NAP in high $\mathrm{Cu}$ concentration $\left(>1 \mathrm{mmol} \mathrm{L}^{-1}\right)$ in adsorption experiment. The ryegrass biomass and the copper accumulation in ryegrass were the highest in MAP among all treatments. The effective order of apatite in phytoremediation of copper contaminated field soil was MAP > NAP > OAP, which was attributed to the high adsorption capacity of copper and the stronger releasing of phosphate by MAP.

Authors' contributions

JX carried out the whole experimental studies, drafted and revised the manuscript. TH participated in the field research and helped to analyze the experimental results. LC designed the experiments and conceived of the study, performed the statistical analysis and drawing. DZ helped to revise the manuscript. All authors read and approved the final manuscript.

\section{Author details}

1 Key Laboratory of Soil Environment and Pollution Remediation, Institute of Soil Science, Chinese Academy of Sciences, Nanjing 210008, China. ${ }^{2}$ University of Chinese Academy of Sciences, Beijing 100049, China.

\section{Acknowledgements}

This research was financially supported by the Project of Science and Technology Service Network Initiative, Chinese Academy of Sciences (KFJ-EW-STS-016) and the National Natural Science Foundation of China $(41471261,21177135)$. The authors thank Dr. Tianran Sun for his constructive suggestions of revamping the manuscript.

\section{Competing interests}

The authors declare that they have no competing interests.

Received: 21 January 2016 Accepted: 2 June 2016

Published online: 26 July 2016

\section{References}

Adrees M, Ali S, Rizwan M et al (2015) The effect of excess copper on growth and physiology of important food crops: a review. Environ Sci Pollut Res 22(11):8148-8162

Adriano DC (2001) Trace elements in terrestrial environments: biogeochemistry, bioavailability, and risks of metals. Springer, New York 
Boisson J, Ruttens A, Mench M et al (1999) Evaluation of hydroxyapatite as a metal immobilizing soil additive for the remediation of polluted soils. Part 1. Influence of hydroxyapatite on metal exchangeability in soil, plant growth and plant metal accumulation. Environ Pollut 104:225-233

Cao XD, Ma LQ, Rhue DR et al (2004) Mechanisms of lead, copper, and zinc retention by phosphate rock. Environ Pollut 131:435-444

Chaturvedi PK, Seth CS, Misra V (2006) Sorption kinetics and leachability of heavy metal from the contaminated soil amended with immobilizing agent (humus soil and hydroxyapatite). Chemosphere 64:1109-1114

Chen XB, Wright JV, Conca JL et al (1997a) Effects of pH on heavy metal sorption on mineral apatite. Environ Sci Technol 31:624-631

Chen X, Wright JV, Conca JL et al (1997b) Evaluation of heavy metal remediation using mineral apatite. Water Air Soil Poll 98:57-78

Chen SB, Zhu YG, Ma YB (2006) The effect of grain size of rock phosphate amendment on metal immobilization in contaminated soils. J Hazard Mater 134:74-79

Chen SB, Ma YB, Chen L et al (2010) Adsorption of aqueous $\mathrm{Cd}^{2+}, \mathrm{Pb}^{2+}, \mathrm{Cu}^{2+}$ ions by nano-hydroxyapatite: single- and multi-metal competitive adsorption study. Geochem J 44:233-239

Chen ZQ, Ai YW, Fang C et al (2014) Distribution and phytoavailability of heavy metal chemical fractions in artificial soil on rock cut slopes alongside railways. J Hazard Mater 273:165-173

Cheung CW, Porter JF, McKay G (2002) Removal of $\mathrm{Cu}(\mathrm{II})$ and Zn(II) ions by sorption onto bone char using batch agitation. Langmuir 18:650-656

Chlopecka A, Adriano DC (1996) Mimicked in situ stabilization of metals in a cropped soil: bioavailability and chemical form of zinc. Environ Sci Technol 30:3294-3303

Corami A, Mignardi S, Ferrini V (2007) Copper and zinc decontamination from single- and binary-metal solutions using hydroxyapatite. J Hazard Mater 146:164-170

Corami A, Mignardi S, Ferrini V (2008) Cadmium removal from single- and multi-metal (Cd plus Pb plus Zn plus Cu) solutions by sorption on hydroxyapatite. J Colloid Interf Sci 317:402-408

Cui HB, Zhou J, Zhao QG et al (2013) Fractions of $\mathrm{Cu}, \mathrm{Cd}$, and enzyme activities in a contaminated soil as affected by applications of micro- and nanohydroxyapatite. J Soil Sediment 13:742-752

Cui HB, Zhou J, Si YB, Mao JD et al (2014) Immobilization of Cu and Cd in a contaminated soil: one- and four-year field effects. J Soil Sediment 14:1397-1406

Drouet C (2015) A comprehensive guide to experimental and predicted thermodynamic properties of phosphate apatite minerals in view of applicative purposes. J Chem Thermodyn 81:143-159

Kaludjerovic-Radoicica T, Raicevicb T (2010) Aqueous Pb sorption by synthetic and natural apatite: kinetics, equilibrium and thermodynamic studies. Chem Eng J 160:503-510

Keller C, Marchetti M, Rossi L et al (2005) Reduction of cadmium availability to tobacco (Nicotiana tabacum) plants using soil amendments in low cadmium-contaminated agricultural soils: a pot experiment. Plant Soil 276:69-84

Knox AS, Kaplan DI, Adriano DC et al (2003) Apatite and phillipsite as sequestering agents for metals and radionuclides. J Environ Qual 32:515-525

Kos B, Lestan D (2004) Chelator induced phytoextraction and in situ soil washing of Cu. Environ Pollut 132:333-339

Laperche V, Traina SJ, Gaddam P et al (1996) Chemical and mineralogical characterizations of Pb in a contaminated soil: reactions with synthetic apatite. Environ Sci Technol 30:3321-3326

Laperche V, Logan TJ, Gaddam P et al (1997) Effect of apatite amendments on plant uptake of lead from contaminated soil. Environ Sci Technol 31:2745-2753

Lindsay WL (2001) Chemical equilibria in soils. The Blackburn Press, New York

Liu RQ, Zhao DY (2007) In situ immobilization of Cu(II) in soils using a new class of iron phosphate nanoparticles. Chemosphere 68:1867-1876

Lu RK (2000) Soil agricultural chemical analysis method. China Agriculture Science and Technique Press, Beijing

Lusvardi G, Malavasi G, Menabue L et al (2002) Removal of cadmium ion by means of synthetic hydroxyapatite. Waste Manage 22:853-857

Ma QY, Traina SJ, Logan TJ et al (1994) Effects of aqueous Al, Cd, Cu, Fe(li), Ni, and Zn on Pb immobilization by hydroxyapatite. Environ Sci Technol 28:1219-1228

Ma QY, Logan TJ, Traina SJ (1995) Lead immobilization from aqueous-solutions and contaminated soils using phosphate rocks. Environ Sci Technol 29:1118-1126

Mackie KA, Marhan S, Ditterich F et al (2015) The effects of biochar and compost amendments on copper immobilization and soil microorganisms in a temperate vineyard. Agr Ecosyst Environ 201:58-69

Miretzky P. Fernandez-Cirelli A (2008) Phosphates for Pb immobilization in soils a review. Environ Chem Lett 6:121-133

Montenegro AC, Ferreyroa GV, Parolo ME et al (2015) Copper speciation in soil: time evolution and effect of clay amendment. Water Air Soil Poll 226:293

Mora ML, Demanet R, Vistoso E et al (2005) Influence of sulfate concentration in mineral solution on ryegrass grown at different $\mathrm{pH}$ and aluminium levels. J Plant Nutr 28:1117-1132

Narasaraju TSB, Phebe DE (1996) Some physico-chemical aspects of hydroxylapatite. J Mater Sci 31:1-21

Rauret G, Lopez-Sanchez JF, Sahuquillo A et al (2000) Application of a modified BCR sequential extraction (three-step) procedure for the determination of extractable trace metal contents in sewage sludge amended reference material (CRM 483), complemented by a three-year stability study of acetic acid and EDTA extractable metal content. J Environ Monitor 2:228-233

Rodriguez-Vila A, Asensio V, Forjan R et al (2015) Chemical fractionation of $\mathrm{Cu}, \mathrm{Ni}, \mathrm{Pb}$ and $\mathrm{Zn}$ in a mine soil amended with compost and biochar and vegetated with Brassica juncea L. J Geochem Explor 185:74-81

Rosas A, Rengel Z, de la Mora Luz M (2007) Manganese supply and pH influence growth, carboxylate exudation and peroxidase activity of ryegrass and white clover. J Plant Nutr 30:253-270

Sandrine B, Ange N, Didier BA et al (2007) Removal of aqueous lead ions by hydroxyapatites: equilibria and kinetic processes. J Hazard Mater 139:443-446 
Smiciklas I, Dimovic S, Plecas I et al (2006) Removal of $\mathrm{Co}^{2+}$ from aqueous solutions by hydroxyapatite. Water Res 40:2267-2274

Sugiyama S, Ichii T, Matsumoto Het al (2002) Effect of calcination and sieving of calcium hydroxyapatite on ionexchangeability with lead cation in the presence and absence of $\mathrm{HCl}$. Adv Environ Res 6:285-289

Sun Y, Xie ZM, Li J et al (2006) Assessment of toxicity of heavy metal contaminated soils by the toxicity characteristic leaching procedure. Environ Geochem Health 28:73-78

Wang YJ, Chen JH, Cui YX et al (2009) Effects of low-molecular-weight organic acids on Cu(II) adsorption onto hydroxyapatite nanoparticles. J Hazard Mater 162:1135-1140

Wang X, Nan ZR, Ding WG et al (2012) Chemical fraction of heavy metals in an oasis soil and their bioavailability to cole crops. Arid Land Res Manag 26:166-180

Xu YP, Schwartz FW, Traina SJ (1994) Sorption of $\mathrm{Zn}^{2+}$ and $\mathrm{Cd}^{2+}$ on hydroxyapatite surface. Environ Sci Technol 28:1472-1480

Zhang ZZ, Li MY, Chen W et al (2010) Immobilization of lead and cadmium from aqueous solution and contaminated sediment using nano-hydroxyapatite. Environ Pollut 158:514-519

\section{Submit your manuscript to a SpringerOpen ${ }^{\mathcal{O}}$} journal and benefit from:

- Convenient online submission

\section{- Rigorous peer review}

- Immediate publication on acceptance

- Open access: articles freely available online

- High visibility within the field

- Retaining the copyright to your article 